\title{
Adapting New Approaches in Quality Assurance Measurement from the Beneficiary Perspective in Kosovo Higher Education
}

\author{
Bujar Gallopeni \\ Gjylbehare Llapi
}

\begin{abstract}
.
Understanding clients' needs and adapting the qualitative provision of services has always been a challenge for higher education institutions, particularly in a reforming education context. In a competitive higher education provision, the overall student satisfaction goes beyond a qualitative education, but including also other important aspects, such as catering, study environment, administration and other important issues. The aim of this study was to adapt new tools for quality assurance in higher education in Kosovo from a comprehensive satisfaction perspective. Internal consistency and inter-theme correlations were examined as a form of questionnaire standardization in an Albanian sample of students. In general, most of examined themes showed moderate to high internal consistency. In addition, almost all themes (in exception of one) showed significant correlations among each other. The study further discusses methodological approaches from a piloting study phase, as well as further research prospects.
\end{abstract}

Keywords: Internal quality assurance, measurement, beneficiary, satisfaction.

\section{Introduction}

Quality assurance in higher education has been one of most focused topics in higher education development in the last decades. Today, almost every country worldwide has adapted sorts of quality assurance policy, in order to guide the higher education development towards economic and societal development needs. Recently, global trends of quality assurance at university level have increased interest on university ranking systems, such as Times Higher Education, Shanghai Ranking, and so on, which are seen as a crucial indicator of university quality assurance.

Quality assurance in higher education was initially adapted from the quality assurance practices used in business organizations. In that perspective, quality assurance has been seen in the importance of involvement of stakeholders and the value they bring in the higher education development (Harvey and Green, 2003). Among important stakeholders in higher education are students, in their role as beneficiaries or clients of higher education service.

From the beginning of the current century, the development of quality assurance standards in the European universities has been collectively guided with the introduction of the European Higher Education Area, known otherwise as Bologna Process. Because Bologna process aims to introduce and guide similar and common principles and standards of higher education in the member countries, the policy of quality assurance has been centralized under the umbrella of European Association for Quality Assurance in Higher Education (ENQA). Following up on recommendations deriving from education ministerial meetings of Bologna member countries, ENQA regularly adopts and revises European Standards and Guidelines for quality assurance (ESG), which guides them down to relevant country authorities to translate them in concrete policies and actions thereby being implemented by respective higher education institutions. In Kosovo, as the socio-economic context of this study focus, ESG have been largely adopted in legal and policy framework, being promoted and overseen by established state authorities, such as Kosovo Accreditation Agency.

A major dimension that ESG focuses is the standards and guidelines for internal quality assurance, which basically guide higher education institutions to have internal policy and structures continually ensuring and checking quality assurance internally. These standards invite higher education institutions to work with stakeholders, and particularly with students in 
different areas of higher education development, like for example in the process of curriculum development and revision, and so on. Consequently, higher education institutions in Kosovo have adapted different practices in the involvement of students, as beneficiary stakeholders, in the internal processes of quality assurance. Among most used practices in this direction is the measurement of students' satisfaction with different aspects of academic life, as a reflection of perceived and experienced qualitative services they receive.

The students' satisfaction measurement by higher education institutions (HEI) in Kosovo, as an internal quality assurance standard, has not a mature tradition yet. This process started quite recently, respectively as a responsive action from the implementation of external quality assurance measures, which started for the first time in Kosovo in 2008, upon establishment and operationalization of Kosovo Accreditation Agency. In many cases, this process is not part of institutional policy, and quite often happens in ad hoc approaches, and different institutions use different dimensions of measuring student's satisfaction. As such, there lacks a common understanding among higher education institutions about such measurement. Consequently, HEls in Kosovo have not managed to establish stable mechanism yet in taking regular measures and collecting relevant information from students in order to continually reflect on the different dimensions of providing services for students. Therefore, relevant measurement approaches considerably lack, but are also necessary to install in the regular actions of HEls. Therefore, the aim of this study was to provide a more comprehensive approach in Kosovo of students' involvement in the quality assurance measurement from the beneficiary/client's perspective. In this dimension, this study has at least two specific objectives. First, we aimed to adapt a common framework for measurement of students' satisfaction, taking into consideration different dimensions that influence the satisfaction among students, such as teaching and learning approaches, academic personnel, campus infrastructure and learning environment, theoretical and practical learning, dormitory and canteen, and so on. And second, we used a piloting approach in a single HEl in order to undertake norming procedures for the adapted instrument used to validate such framework.

\section{Methodology}

In relation to the first objective we adapted two previously established frameworks of measuring student satisfaction. First, we used a European approach, respectively the Student Satisfaction Questionnaire, developed under a framework of European Lifelong Learning project financed by Leonardo da Vinci scheme (Quality in VET schools, 2005), which has more focus on development of skills and competences reflecting on the learning environment and resources put by education institutions. And second, we used the National Student Survey used in the United Kingdom higher education institutions (Higher Education Funding Council for England - HEFCE, 2014), because the first collective quality assurance external and internal evaluation in Kosovo was conducted by British Council, thereby in many of the cases reflecting on the British system of quality assurance.

Whereas, related to the second objective we used a pilot study perspective, employing quantitative methodology and data collecting from a single higher education institutions, the University for Business and Technology (UBT).

\subsection{Sample}

In this pilot study phase, we employed a purposive sample method for data collection, in main UBT study areas, and included 300 students of undergraduate studies, mainly enrolled over a five-year period.

Table 1. Sample distribution

\begin{tabular}{llcc}
\hline Sample category & Sample category unit & N & $\%$ \\
\hline Gender & Female & 111 & 37 \\
& Male & 187 & 63 \\
\hline Study field & Management, Business and Economy & 35 & 11.7 \\
& Computer Engineering & 103 & 34.3
\end{tabular}


Architecture

Media \& Communication

Other
95

50

17

1

13

6

27

100

150
31.7

16.7

5.7

Enrolment year

$\begin{array}{lcc}2011 / 2012 & 13 & 4.4 \\ 2012 / 2013 & 6 & 2 \\ 2013 / 2014 & 27 & 9.1 \\ 2014 / 2015 & 100 & 33.7 \\ 2015 / 2016 & 150 & 50\end{array}$

\section{Data Collection}

The adapted framework for measuring student satisfaction in this study has two sections. First section contains individual and program information, such as student's gender, age, year of enrolment, and study program. The second section contains 54 items clustered in 10 main themes listed below, and scored in a five-point Likert scale: $0=1$ do not agree, $1=$ I slightly agree, 2 = I agree on average, $3=$ I agree, and $4=$ I agree a lot.

Questionnaire main themes:

Teaching and staff ( 7 items)

Assessment and feedback (6 items)

Learning sources and library (4 items)

Academic support and advising (6 items)

Admin support and organization ( 3 items)

Personal/Professional development ( 3 items)

Facilities and infrastructure (10 items)

Canteen (4 items)

Practical learning/internship (7 items)

Overall satisfaction (4 items)

In this piloting phase, the questionnaire was prepared in the form of paper-and-pencil, and administered by two trained students form the Faculty of Management, Business and Economy. 


\section{Data Analysis and Results}

We followed a four-step methodological approach of questionnaire adaptation and testing.

In the first step, using the two indicated frameworks we adapted the study questionnaire framework, with relevant themes related to student satisfaction, as well as the measurement scale, as described in the previous section. In the second step, we translated the questionnaire in Albanian using a double-checking approach from two independent translators. The third step followed with data collection. And in the fourth step finally, reliability and correlational analysis were performed.

Reliability analysis (as presented in table no.2) show a relatively high internal consistency, except a few themes, respectively assessment and feedback, admin support and organization, and teaching and staff, which showed moderate consistency.

Table 2. Reliability analysis

Theme

Facilities and infrastructure

Canteen

Personal/Professional development

Overall satisfaction

Learning sources and library

Academic support and advising

Assessment and feedback

Almost all inter-theme correlations are statistically significant, with the exception of practical learning/internship theme, which does not give any significant relationship with other themes, except with themes of canteen, and overall satisfaction. In addition, the dimension of overall satisfaction show in general low correlation values, but in many cases statistically significant, except with two themes, such as teaching sources and library, and academic support and advising, which has no significant relation. Interestingly, the theme of overall satisfaction has significant and stronger relationship only with the theme of practical learning/ internship, which one has no significant relations with none of other themes. These results suggest that particularly the themes of overall satisfaction, and practical learning/ internship needs some or major revision in terms of adaption of included items in Albanian population and the measurement context. 


$\begin{array}{lllllllll}1 & 2 & 3 & 4 & 5 & 6 & 7 & 8 & 9\end{array}$

1. Staff and learning

2. Assessment and feedback

3. Teaching sources and library

4. Academic support and advising

5. Admin. support and organization

6. Professional/ personal development

7. Facilities and infrastructure

8. Canteen

9. Practical learning/ internship

10. Overall satisfaction
$.392^{* *}$

$.331^{* *} .539^{* *}$

$.316^{* *} .465^{\star *} .435^{\star *}$

$.318^{\star \star} .437^{\star \star} .368^{\star \star} \cdot 608^{\star \star}$

$.212^{* *} .346^{* *} .241^{* *} .516^{* *} \quad .698^{* *}$

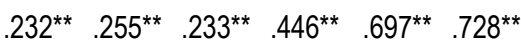

$.258^{* *} .279^{* *} .264^{* *} .360^{* *} .564^{* *} .431^{* *} \cdot .530^{* *}$

$\begin{array}{llllllll}0,073 & 0,004 & 0,008 & -0,063 & 0,064 & 0,086 & 0,108 & .144^{*}\end{array}$

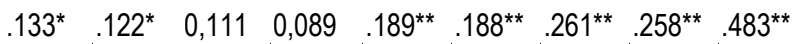

${ }^{* *}$ Correlation is significant at the 0.01 level (2-tailed).

${ }^{*}$ Correlation is significant at the 0.05 level (2-tailed).

\section{Discussion}

In the time of diversification of higher education provision, as well as taking into consideration the developing dimension of higher education sector in a rapidly changing socio-economic context, such as Kosovo's, focusing on the provision of education services taking account for client's needs is more than necessary. To the knowledge of authors, this study provides first efforts regarding adaption of measurement approaches of student satisfaction in the Kosovo context, using testing standardization methods.

As a first step to adapt new methodological approaches in this direction, we provide an initial framework to measurement of student satisfaction in an Albanian population and socio-economic context. In this direction, however, the results in this pilot study show that in general the adapted framework has good a ground of reliability and validity of the measurement instrument, therefore slight changes should be considered in the future use of this measurement instrument, particularly in the dimension of validity.

Nonetheless, future research should consider the use of this framework in a larger population sample and in a high number of higher education institutions, as well as in all study cycles. 


\section{References}

[1] European Association for Quality Assurance in Higher Education (ENQA). Standards and Guidelines for Quality Assurance in the European Higher Education Area (ESG). (2015). Brussels, Belgium.

[2] Harvey, L. and Green, D. (1993) Defining quality, Assessment and Evaluation in Higher Education, Vol. 18, No. 1

[3] Higher Education Funding Council for England - HEFCE. (2014). National Student Survey. Retrieved on 16-092016: http://www.thestudentsurvey.com/content/NSS2017_Core_Questionnaire.pdf

[4] Quality in VET schools (2005). Student Satisfaction Survey. Retrieved on 14-09-2016: http://www.oph.fi/download/133510_efqm_ssq_en.pdf 